\title{
Effects of drugs on bone metabolism in a cohort of individuals with traumatic spinal cord injury
}

\author{
Christina Kokorelis ${ }^{1,2} \cdot$ Marlis Gonzalez-Fernandez ${ }^{2} \cdot$ Marjorie Morgan $^{1} \cdot$ Cristina Sadowsky $\mathbb{C l}^{1,2}$
}

Received: 29 August 2018 / Revised: 4 December 2018 / Accepted: 10 December 2018

(C) International Spinal Cord Society 2019

\begin{abstract}
Study Design: This study is a retrospective review examining the prevalence of drugs commonly used in the management of spinal cord injury (SCI) which may influence bone health.

Objective: The aim of our study was to examine the role commonly prescribed medications play in post-SCI bone health. Setting: We included all males 21 years of age and older who were evaluated over a 10-year period at an SCI-specialized center for a trauma-induced SCI.

Method: We compared characteristics of individuals with normal bone mass to those with low bone mass according to their dual-energy X-ray absorptiometry (DXA) scan. Medication lists were reviewed for the presence of drugs considered to either positively or negatively affect bone metabolism.

Results: Comparing individuals with normal bone mass $(n=68)$ to those with low bone mass $(n=211)$, only "Time after Injury" and "Level of Injury" were found to influence the likelihood of having low bone mass. Multivariate analysis failed to demonstrate significant associations between bone mass and the sum of drugs which either positively or negatively affect bone metabolism. When medications were reviewed individually, only bisphosphonates and anticonvulsants were found to be significantly associated with bone mass.

Conclusions: Although $76 \%$ of our cohort was found to have low bone mass, the only major risk factors were "Time after Injury" and "Level of Injury". Anticonvulsant use was more common in individuals with low bone mass compared to those with normal bone mass. Given the retrospective methodology of this work, our findings underline associations that warrant further investigation.
\end{abstract}

Keywords: Spinal cord injury $\cdot$ Bone health $\cdot$ Low bone mass $\cdot$ Medication use $\cdot$ Anticonvulsants

\section{Introduction}

The majority of spinal cord injuries (SCIs) are caused by physical trauma such as motor vehicle accidents, gunshots, falls, and sports injuries, and are consequently described as traumatic spinal cord injuries (tSCI). The prevalence of

Supplementary information The online version of this article (https:// doi.org/10.1038/s41394-018-0146-8) contains supplementary material, which is available to authorized users.

Christina Kokorelis

Kokorelis@kennedykrieger.org

1 Kennedy Krieger Institute, 707 N. Broadway, Baltimore, MD 21205, USA

2 Johns Hopkins University, 600 N. Wolfe St., Baltimore, MD 21287, USA
tSCIs in the United States is estimated to be between 245,000 and 353,000, with an annual incidence of 54 cases/ million population or approximately 17,500 new tSCI cases each year [1]. Life expectancy appears to be near normal for individuals with paralysis, especially for those with less severe injuries [1]. Nevertheless, living with chronic paralysis exposes individuals to several complications throughout their lifetime [2]. Bone loss is a well-recognized complication of SCI; it tends to begin immediately after injury, particularly at the sub-lesional level, and continues at a rate of $1 \%$ per week in areas of dominant trabecular bone for the first year after injury [3,4]. Although the rate of bone loss tends to slow down after the first year, bone loss continues to occur long afterwards [5].

The rate of bone loss is substantially greater after acute SCI compared to other conditions associated with immobilization. Several mechanisms specific to SCI are likely responsible for this phenomenon; the severity of the 


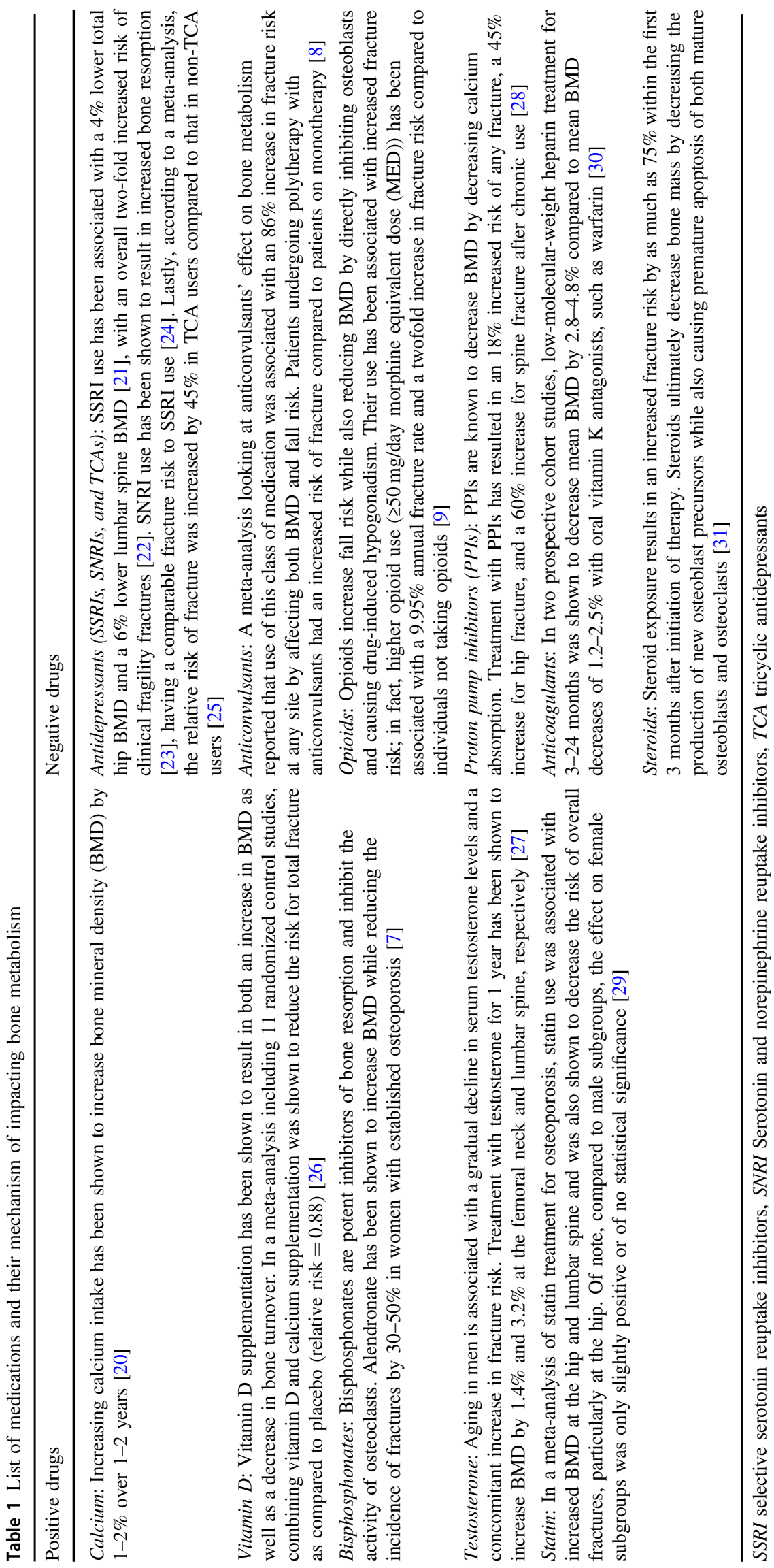


immobilization, the loss of positive central and peripheral neural influences to the sub-lesional bone, the loss of essential anabolic factors, the administration of catabolic factors at the time of injury, and the subsequent use of commonly prescribed pharmacologic agents may all play a role [6].

A number of commonly prescribed medications have been shown to either positively or negatively affect bone mass, bone density, and consequently, fracture risk in the general population (Table 1). For example, bisphosphonates, the most commonly prescribed drug class to treat osteoporosis, are potent inhibitors of bone resorption and inhibit the activity of osteoclasts. Alendronate has been shown to increase bone mineral density (BMD) while reducing the incidence of fractures by $30-50 \%$ in women with established osteoporosis [7]. In contrast, a metaanalysis looking at anticonvulsants' effect on bone metabolism reported that use of this medication class was associated with an $86 \%$ increase in fracture risk at any site by affecting both BMD and fall risk. Patients undergoing polytherapy with anticonvulsants had an increased risk of fracture compared to patients on monotherapy [8]. Opioids also negatively affect bone metabolism; they increase fall risk while also reducing BMD by directly inhibiting osteoblasts and causing drug-induced hypogonadism. Their use has been associated with increased fracture risk. In fact, a high daily opioid dose ( $\geq 50 \mathrm{mg} /$ day morphine equivalent dose (MED)) has been associated with a $9.95 \%$ annual fracture rate and a twofold increase in fracture risk compared to individuals not taking opioids [9].

The aim of our study was to retrospectively examine the role commonly prescribed pharmacologic agents play in post-tSCI bone metabolism. We hypothesized that the use of these drugs which are known to either positively or negatively affect bone metabolism in the general population is associated with changes in bone mass in individuals with tSCI-related paralysis, independent of time after injury.

\section{Methods}

Data utilized in this analysis were obtained from an ongoing Institutional Review Board-approved clinical outcomes database maintained since 2005 in a tertiary care center caring for individuals with SCI. Persons of all ages with SCI-related paralysis are entered in this database upon initial evaluation at the center. The database stores demographic, injury, therapy, and clinical outcome measurements that are recorded routinely during medical and therapeutic interventions occurring at the center.

For this analysis, we included all males 21 years of age and older with traumatic complete or incomplete (American Spinal Injury Association Impairment Scale (AIS) A to D)
SCI who were evaluated at the center over a 10 -year period, between June 2005 and June 2015. Women were excluded from this analysis to avoid menopause as a potential confounder. This study was approved by the Institutional Review Board of the institution where the clinical database is housed.

In addition, each individual included in our cohort had undergone at least one bone mass assessment utilizing a dual-energy X-ray absorptiometry (DXA) scan. As defined by the National Osteoporosis Foundation, bone mass was considered "low" if the Z-score was less than -2.0 for individuals under the age of 50 , or the $T$-score was less than -1.0 (osteopenia or osteoporosis) for individuals 50 years and older [10].

The medications lists for these individuals from all outpatient visits to the center prior to their first DXA scan were thoroughly reviewed for the presence of pharmacologic agents considered to either positively or negatively affect bone metabolism (Table 1). For the purpose of this study, we operationally defined use of a medication as continuous use for one year or more prior to DXA scan occurrence (Table 2).

All analyses were performed by comparing demographic and study characteristics between individuals with low bone mass and those with normal bone mass based on their $Z$ or $T$ scores. Characteristics included Race (Caucasian vs African American vs Other), Degree of Motor Completeness (Complete vs Incomplete), History of Pathologic Fracture (Yes vs No), Community Ambulatory Status (Yes vs No), and Functional Electrical Stimulation (FES) usage (Yes vs No), defined as at least $10 \mathrm{~min} /$ week for at least 1 month. Classic tests of hypotheses were used including $t$-tests, $\mathrm{chi}^{2}$, and Fisher's exact tests as applicable to compare the characteristics of the groups.

A logistic regression model was created to understand the contribution of demographic and injury characteristics,

Table 2 Medication use in a tSCI cohort $(n=279)$ prior to DXA scan

\begin{tabular}{ll}
\hline Medication & $\begin{array}{l}\text { Number of individuals taking each } \\
\text { medication for 1 year or more }(n=279)\end{array}$ \\
\hline Vitamin D & 135 \\
Calcium & 102 \\
Bisphosphonates & 27 \\
Testosterone & 22 \\
Statins & 17 \\
AntiDepressants & 81 \\
Anticonvulsants & 122 \\
Opioids & 91 \\
Proton pump inhibitors & 43 \\
Steroids & 18 \\
Anticoagulants & 36 \\
\hline
\end{tabular}


Table 3 Demographic, injury, and treatment characteristics in a cohort of males with traumatic spinal cord injury, $n=279$

\begin{tabular}{|c|c|c|c|}
\hline Factor & $\begin{array}{l}\text { Normal bone } \\
\text { mass }(n=68)\end{array}$ & $\begin{array}{l}\text { Low bone mass }{ }^{\mathrm{a}} \\
(n=211)\end{array}$ & $P$-value \\
\hline Race condensed, $n(\%)$ & & & 0.52 \\
\hline Caucasian/White & $38(55.9)$ & $133(63)$ & \\
\hline African American/Black & 14 (20.6) & $40(19)$ & \\
\hline $\begin{array}{l}\text { Other (Hispanic, Asian, } \\
\text { and Other) }\end{array}$ & $16(23.5)$ & $38(18)$ & \\
\hline Motor, $n(\%)$ & & & 0.31 \\
\hline Complete & $31(45.6)$ & $111(52.6)$ & \\
\hline Incomplete & $37(54.4)$ & $100(47.4)$ & \\
\hline Level, $n(\%)$ & & & 0.04 \\
\hline Tetraplegia & $33(48.5)$ & $132(62.6)$ & \\
\hline Paraplegia & $35(51.5)$ & $79(37.4)$ & \\
\hline $\begin{array}{l}\text { History of pathologic } \\
\text { fracture }\end{array}$ & $19(27.9)$ & $73(34.6)$ & 0.31 \\
\hline $\begin{array}{l}\text { Functional electrical } \\
\text { stimulation user, } n(\%)\end{array}$ & $43(63.2)$ & $134(63.5)$ & 0.97 \\
\hline $\begin{array}{l}\text { Community ambulator, } n \\
(\%)\end{array}$ & $10(14.7)$ & $26(12.3)$ & 0.61 \\
\hline Time after injury, $n(\%)$ & & & 0.02 \\
\hline$<1$ year from injury & $45(66.2)$ & $105(49.8)$ & \\
\hline$>1$ year from injury & $23(33.8)$ & $106(50.2)$ & \\
\hline
\end{tabular}

${ }^{a}$ Low bone mas defined as a $Z$-score less than -2.0 for individuals under the age of 50 or a $T$-score less than -1.0 for individuals 50 years and older

Bold values are of significant value, with $p$ values $<.05$

including age, race, and time after injury to the loss of bone mass. To determine the role of various drugs on bone metabolism in our cohort, the use of each medication was added to the regression model one at a time. A variable grouping the aforementioned drugs into two groups, one combining those drugs with a positive effect on bone mass ("positive drugs") and the other combining the drugs with a negative effect on bone mass ("negative drugs"), was also created but failed to demonstrate any difference by group (Supplemental Data). Analyses were performed using Stata IC, 11, StataCorp LP, College Station, TX.

\section{Results}

Of the 279 men with tSCI, $211(76 \%)$ met our criteria for low bone mass. As seen in Table 3, upon comparing the individuals in our cohort with normal bone mass $(n=68)$ to those with low bone mass $(n=211)$, we found no significant difference in Race $(p=0.52)$, Degree of Motor Completeness $(p=0.31)$, History of Pathologic Fracture $(p=0.31)$, Community Ambulatory Status $(p=0.61)$, or FES usage $(p=0.97)$ between the two groups. There were, however, two factors that were significantly different between the two groups: "Time after Injury", with those individuals with injuries $<1$-year-old having a significantly lower incidence of low bone mass compared to those with more chronic injuries $(p=0.02)$, and "Level of Injury", with individuals with paraplegia having a significantly lower incidence of low bone mass compared to individuals with tetraplegia $(p=0.04)$.

Overall, a total of 92 individuals (33\%) in our cohort had a history of low-impact, pathologic bone fracture, similar to previously reported figures in the SCI population [11]: 50 individuals had one pathologic fracture, 21 had two fractures, 19 had three fractures, and 2 had a total of four fractures each. Interestingly, in our cohort, having low bone mass was not associated with suffering a low-impact, pathologic fracture $(p=0.31)$.

Of the 279 men, $157(56.3 \%)$ had taken at least one drug known to have a positive effect on bone metabolism, while $191(68.5 \%)$ had taken at least one drug known to negatively affect bone metabolism. When grouped, there was no significant difference in the use of "positive drugs" ( $p=$ $0.52)$ or "negative drugs" $(p=0.18)$ between individuals in our cohort who had normal bone mass and those who had low bone mass.

Multivariate analysis using a logistic regression model did not demonstrate increased odds of developing low bone mass for demographic characteristics typically associated with lower bone mass in the general population such as age and race. In contrast, "Time after Injury", namely $>1$ year, was a strong predictor of low bone mass in our cohort (Table 4).

Evaluation of each medication in the context of the aforementioned model failed to demonstrate significant associations when the "positive drugs" and the "negative drugs" were grouped. However, when each medication class was added independently, the use of bisphosphonates and anticonvulsants was found to be significantly associated with bone mass status (Table 4).

\section{Discussion}

This study is a retrospective analysis examining the prevalence of drugs commonly used in the management of tSCI which may be contributing to altered bone metabolism. Given that SCI patients who survive their first year postinjury are expected to live between 8 and 53 years after paralysis onset depending on their age and level of injury, they are likely to be exposed to several medications throughout their lifetime [1].

While age and race are known to influence bone mass in the general population, our analysis of tSCI males did not, surprisingly, show the same associations. Additionally, our results demonstrated that neither FES usage nor community ambulatory status was associated with increased bone mass, in contrast to several previous reports [12-14]. Although there are no studies specifically looking at the effects of 


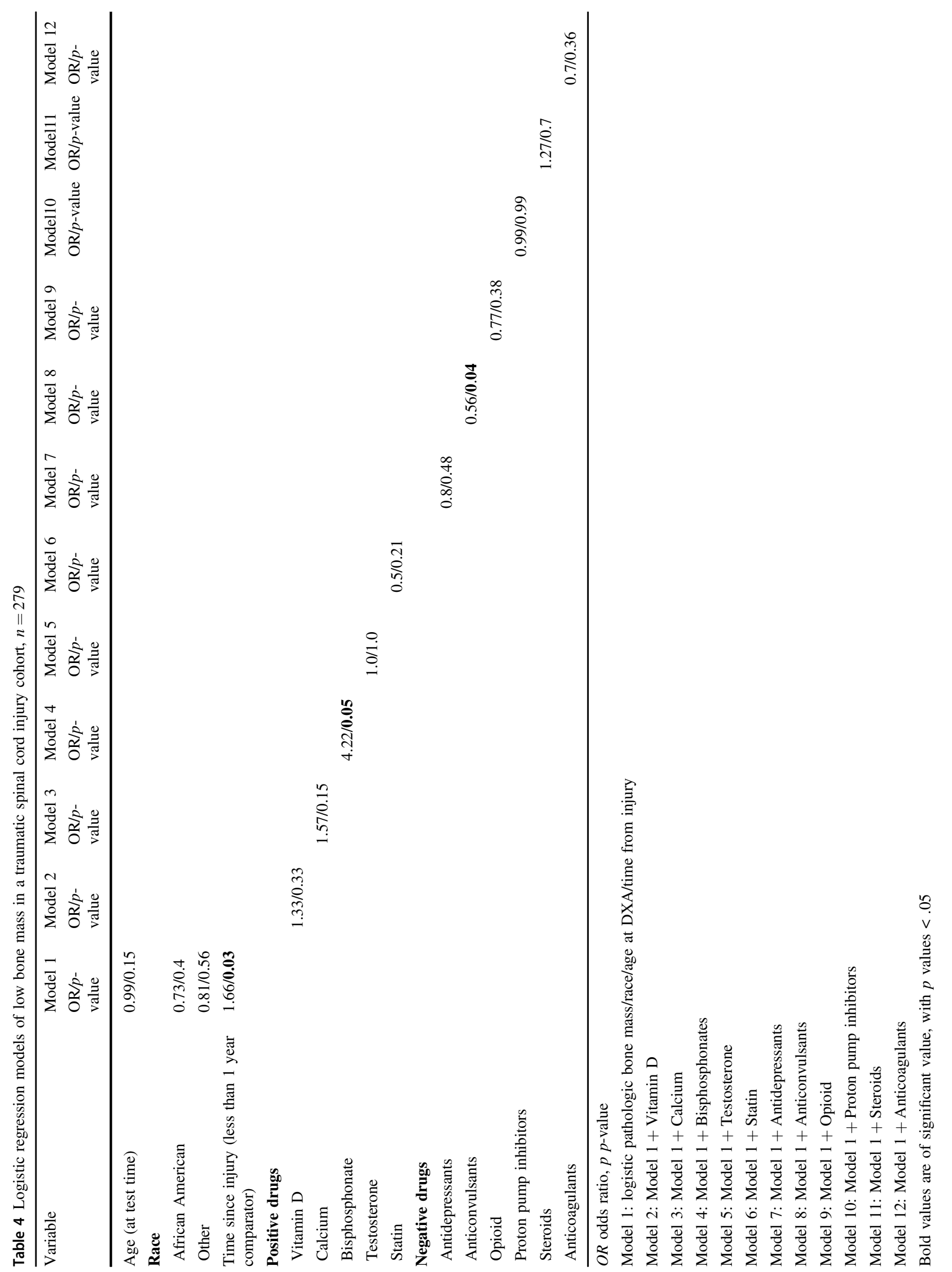


ambulation on bone health in tSCI individuals, one cross-sectional comparative study $(n=31)$ found that individuals with paraplegia who used standing frames had significantly higher bone mass than those who did not use standing frames as measured by quantitative computed tomography [15]. In contrast, our findings suggest that maintaining the ability to ambulate does not ensure preservation of bone mass in individuals with paralysis. This finding supports the hypothesis that the mechanism of bone loss in tSCI is multi-factorial and is not solely due to the loss of weight loading on bones.

Although $76 \%$ of our tSCI cohort was found to have low bone mass, the only major risk factors for low bone mass were "Time after Injury", with longer time ( $>1$ year) from injury being a strong predictor of low bone mass, and "Level of Injury", with individuals with tetraplegia having significantly lower bone mass than individuals with paraplegia. Furthermore, having low bone mass in our study was not associated with sustaining a low-impact, pathologic fracture, in contrast to previous findings [16]. The lack of association between low bone mass and factors known to predispose to low bone mass in the general population such as age, race, and history of previous fracture is also likely due to the multi-factorial etiology of bone loss in our tSCI population.

We also did not find a significant association between bone mass and the sum of drugs which either positively or negatively affect bone metabolism. When looking at each drug class individually, bisphosphonates were the only "positive drug" class significantly associated with bone mass. In fact, bisphosphonates were more commonly encountered in individuals with low bone mass compared to individuals with normal bone mass $(\mathrm{OR}=4.22)$. The likely explanation is that bisphosphonates had been started to treat the low bone mass state. Among the "negative drugs", only anticonvulsants were found to have a significantly different prevalence in the two populations. Anticonvulsants were found to be more commonly used by individuals with low bone mass compared to those with normal bone mass (OR $=0.56$ ). Carbone et al. [17] have similarly shown that the use of anticonvulsants in SCI patients is associated with an increased risk of fractures.

Limitations to this study include grouping medications into classes such as bisphosphonates and not further subdividing these classes into individual medications (i.e. oral medications such as etidronate versus injectables like zolendronic acid, an IV infusion). In the largest systematic review of randomized control trials (RCTs) looking at bone mass after tSCI, moderate-quality evidence was found for the effectiveness of zolendronic acid in preventing bone loss in acute SCI. In contrast, there was only very low-quality evidence for etidronate use, suggesting that different medications in the same class may have varying effects on bone mass in the tSCI population [18].
Due to low usage, we ultimately excluded denosumab, a human monoclonal antibody to RANKL and a novel immunological/pharmacological FDA-approved approach for the treatment of osteoporosis, from our analysis. Analyses of bone density and bone turnover rate have demonstrated the effects of denosumab on bone remodeling to be more effective than those of bisphosphonates [6].

This study also could not tease out the intensity and duration of some of the physical interventions assumed to help bone mass preservation and/or deposition (i.e. community ambulatory status and usage of FES ergometry). Bauman et al. [6] have shown that FES using cyclical muscle contraction appears to be beneficial to bone mass when initiated at the time of injury; however, the effect is more nebulous when FES is performed in individuals with chronic SCI. Similarly, the only RCT looking at the effects of non-pharmacologic modalities in chronic SCI did not show any benefit to low-intensity FES but did show modest benefit on bone health with higher-intensity FES [19]. At this time, there is no published data exploring the effectiveness of simultaneous administration of pharmacologic therapy with non-pharmacologic intervention on bone health in SCI.

Given the retrospective methodology of this work, our findings underline associations that warrant further investigation. Ultimately, it is important to prospectively assess the role of different pharmacologic agents on bone mass in the tSCI population, as low bone mass is a common comorbidity associated with paralysis with both economic and quality of life implications.

\section{Compliance with ethical standards}

Conflict of interest The authors declare that they have no conflict of interest.

Publisher's note: Springer Nature remains neutral with regard to jurisdictional claims in published maps and institutional affiliations.

\section{References}

1. Spinal Cord Injury (SCI) Facts and Figures at a Glance. https://www.nscisc.uab.edu/Public/Facts\%202016.pdf/ [Accessed 19th 2017].

2. Varzi D, Coupaud SAD, Purcell M, Allan DB, Gregory JS, Barr RJ. Bone morphology of the femur and tibia captured by statistical shape modelling predicts rapid bone loss in acute spinal cord injury patients. Bone. 2015;81:495-501.

3. Szollar SM, Martin EM, Sartoris DJ, Parthemore JG, Deftos LJ. Bone mineral density and indexes of bone metabolism in spinal cord injury. Am J Phys Med Rehabil. 1998;77:28-35.

4. Garland D, Adkins R, Stewart CA. Five-year longitudinal bone evaluations in individuals with chronic complete spinal cord injury. J Spinal Cord Med. 2008;31:543-50.

5. Eser P, Frotzler A, Zehnder Y, Wick L, Knecht H, Denoth J, et al. Relationship between the duration of paralysis and bone structure: 
a pQCT study of spinal cord injured individuals. Bone. 2004;34:869-80.

6. Bauman WA, Cardozo CP. Osteoporosis in individuals with spinal cord injury. Pm\&R. 2015;7:188-201.

7. Black DM, Cummings SR, Karpf DB, Cauley JA, Thompson DE, Nevitt MC, et al. Randomised trial of effect of alendronate on risk of fracture in women with existing vertebral fractures. Fracture Intervention Trial Research Group. Lancet. 1996;348:1535-41.

8. Shen C, Chen F, Zhang Y, Guo Y, Ding M. Association between use of antiepileptic drugs and fracture risk: a systematic review and meta-analysis. Bone. 2014;64:246-53.

9. Saunders KW, Dunn KM, Merrill JO, Sullivan M, Weisner C, Braden JB, et al. Relationship of opioid Uue and dosage levels to fractures in older chronic pain patients. J General Intern Med. 2010;25:310-5.

10. National Osteoporosis Foundation. Bone density exam/testing. https://www.nof.org/patients/diagnosis-information/bone-densityexamtesting/ [Accessed 19th June 2017].

11. Troy KL, Morse LR. Measurement of bone: diagnosis of SCIinduced osteoporosis and fracture risk prediction. Top Spinal Cord Inj Rehabil. 2015;21:267-74.

12. deBruin ED, Frey-Rindova P, Herzog RE, Dietz V, Dambacher MA, Stüssi E. Changes of tibia bone properties after spinal cord injury: effects of early intervention. Arch Phys Med Rehabil. 1999;80:214-20.

13. Dudley-Javoroski S, Shields RK. Asymmetric bone adaptations to soleus mechanical loading after spinal cord injury. J Musculoskelet Neuron Interact. 2008;8:227-38.

14. Dudley-Javoroski S, Saha PK, Liang G, Li C, Gao Z, Shields RK. High dose compressive loads attenuate bone mneral loss in humans with spinal cord injury. Osteoporos Int. 2012;23:2335-46.

15. Dionyssiotis Y, Lyritis GP, Mavrogenis AF, Papagelopoulos PJ. Factors influencing bone loss in paraplegia. Hippokratia. 2011;15:544-59.

16. Lazo MG, Shirazi P, Sam M, Giobbie-Hurder A, Blacconiere MJ, Muppidi M. Osteoporosis and risk of fracture in men with spinal cord injury. Spinal Cord. 2001;39:208-14.

17. Carbone L, Chin AS, Lee TA, Burns SP, Svircev JN, Hoenig H, et al. The association of anticonvulsant use with fractures in spinal cord injury. Am J Phys Med Rehabil. 2013;92:1037-050.

18. Soleyman-Jahi S, Yousefian A, Maheronnaghsh R, Shokraneh F, Zadegan SA, Soltani A, et al. Evidence-based prevention and treatment of osteoporosis after spinal cord injury: a systematic review. Eur Spine J. 2018;27:1798-814.
19. Johnston TE, Marino RJ, Oleson CV, Schmidt-Read M, Leiby BE, Sendecki J, et al. Musculoskeletal effects of 2 functional electrical stimulation cycling paradigms conducted at different cadences for people with spinal cord injury: a pilot study. Arch Phys Med Rehabil. 2016;97:1413-22.

20. Tai V, Leung W, Grey A, Reid IR, Bolland MJ.Calcium intake and bone mineral density: systematic review and meta-analysis. BMJ. 2015;351:h4183

21. Haney EM, Chan BK, Diem SJ, Ensrud KE, Cauley JA, BarrettConnor E, et al. Association of low bone mineral density with selective serotonin reuptake inhibitor use by older men. Arch Intern Med. 2007;167:1246-51.

22. Richards JB, Papaioannou A, Adachi JD, Joseph L, Whitson HE, Prior JC, et al. Effect of selective serotonin reuptake inhibitors on the risk of fracture. Arch Intern Med. 2007;167:188-94.

23. Shea ML, Garfield LD, Teitelbaum S, Civitelli R, Mulsant BH, Reynolds CF,III. et al. Serotonin-norepinephrine reuptake inhibitor therapy in late-life depression is associated with increased marker of bone resorption. Osteoporos Int. 2013;24:1741-9.

24. Wang CY, Fu SH, Wang CL, Chen PJ, Wu FL, Hsiao FY. Serotonergic antidepressant use and the risk of fracture: a populationbased nested case-control study. Osteoporos Int. 2016;27:57-63.

25. Wu Q, Qu W, Crowell MD, Hentz JG, Frey KA. Tricyclic antidepressant use and risk of fractures: a meta-analysis of cohort and case-control studies. J Bone Miner Res. 2013;28:753-63.

26. Chung M, Lee J, Terasawa T, Lau J, Trikalinos TA. Vitamin D with or without calcium supplementation for prevention of cancer and fractures: an updated meta-analysis for the U.S. Preventive Services Task Force. Ann Intern Med. 2011;155:827-38.

27. Giannoulis MG, Martin FC, Nair KS, Umpleby AM, Sonksen P. Hormone replacement therapy and physical function in healthy oder men. Time to talk hormones? Endocr Rev. 2012;33:314-77.

28. Vestergaard P, Rejnmark L, Mosekilde L. Proton pump inhibitors, histamine $\mathrm{H} 2$ receptor antagonists, and other antacid medications and the risk of fracture. Calcif Tissue Int. 2006;79:76-83.

29. An T, Hao J, Sun S, Li R, Yang M, Cheng G, et al. Efficacy of statins for osteoporosis: a systematic review and meta-analysis. Osteoporos Int. 2017;28:47-57.

30. Gajic-Veljanoski O, Phua CW, Shah PS, Cheung AM. Effects of long-term low-molecular-weight heparin on fractures and bone density in non-pregnant adults: a systematic review with metaanalysis. J Gen Intern Med. 2016;31:947-57.

31. Weinstein RS. Glucocorticoid-induced osteoporosis and osteonecrosis. Endocrinol Metab Clin North Am. 2012;41:595-611. 